Una reflexión indulgente sobre la traducibilidad poética, y

claves de Zubieta de Arriagada Zubieta:

el espacio como condicionante a la traducibilidad

y la mediación crítica de lo (in)antologable

Jorge Luis Pérez Armijos

jl.perez.armijos@gmail.com

Universidad de Barcelona

Invierno de 2019

«Stylistic restrictions are a particularly important element in the translation of poetry, for so much of the essence of poetry consists in a formal envelope for meaningful content». -Eugene Nida

Hay obviedades que, sea por su naturaleza axiomática o su pronta interiorización, a veces, olvidamos. En el presente ensayo no se descubre nada, se recuerda y discute sobre ciertos asuntos inherentes a la difusión de la poesía postmoderna cuando esta se traduce o reseña antológicamente, acusando, entre otros, los problemas del espacio de lo traducido; ésta reflexión nace a través de la lectura y valoración del poemario Zubieta del chileno Rodrigo Arriagada Zubieta. ${ }^{1}$

\title{
1. Problemas de la postmodernidad poética
}

«Between the frivolity and the insincerity, between the ignorance and the irrelevant learning, the outlook for a literary criticism in our time is dark». -Allen Tate

Es un problema exclusivo de la poesía. Lo fuera también de la música, pero esta, aún cuando se traduce, no se traduce entera. Y es un problema reciente, nacido de la actual borrosa frontera entre la narrativa prosaica y la poesía.

Empecemos con un ejemplo que requiere muchas lenidades de parte de cualquier criterio: una indulgencia, entonces. Tomemos un poema de Sor Juana: el del íncipit «En perseguirme, Mundo, ¿̇qué interesas?». A pesar de Benjamin, digamos que

\footnotetext{
1 Rodrigo Arriagada Zubieta, Zubieta, 1. ${ }^{a}$ ed. (Buenos Aires: Buenos Aires Poetry, 2019).
} 
éste soneto se puede traducir. Digamos, además, que se traduce bien. Al alemán, digamos. El poema ahora permite a un alemán el mismo conocimiento que permite a, digamos, un ecuatoriano. En este esfuerzo, la unidad poética ha quedado completamente traducida -si Sor Juana permitiera tal presunción. El alemán sabe ahora algo de la obra de Sor Juana. Quizás se anime a leer más de ella, o de su traductor, pues puede argumentar que tiene cierto conocimiento sobre sus quehaceres poéticos -no reparemos en las indulgencias exigidas para equiparar la recepción del poema, cuestión que, por otro lado, es inútil. La cuestión aquí es la fragmentabilidad. Ciertos modos poéticos, sobretodo aquellos previos a la postmodernidad, permitían fragmentabilidad. Ahora, ése no es el caso.

La poesía de Zubieta -y la poesía posmoderna, en general- sólo se puede entender como parte de su contexto. Y he aquí no el descubrimiento, si no la obviedad. Pero esta obviedad es obviada, quizás deliberadamente, o al momento de traducir un poema, o al antologarlo, o al entender el concepto de la unidad poética y dónde ésta yace.

1.1 Lo antologable: el todo y sus partes

$$
\begin{array}{r}
\text { «Unreal City, } \\
\text { Under the brown fog of a winter dawn». } \\
- \text { T.S. Elliot }
\end{array}
$$

En julio de 2017 Adrián Cárdenas montó en un microteatro guayaquileño Ezequiel 25:17, una representación de una escena de Pulp Fiction. En la representación de lo que sería en la película la escena final -la escena del asalto al restaurante- los ladrones irrumpían en la sala del teatro con tal tesón que en más de una ocasión más de un espectador se llevó un susto. Éstos espectadores -que evidentemente no conocían Pulp FIction- podrían decir, si acaso, que disfrutaron de Ezequiel 25:17, mas no que han disfrutado de Pulp Fiction. Es tan evidente que deja de serlo. 
Aún más, supongamos que un espectador vea únicamente sólo esa misma escena en Pulp Fiction. ¿Puede decir que conoce la totalidad de la obra? La suma de las partes es mayor a sus partes. Este hipotético receptor podría haber disfrutado de la escena, podría recomendarla, mas no puede aún decir que conoce la totalidad de Pulp Fiction, y no puede, entonces, si intenta ser justo, valorarla, pues el conocimiento de la totalidad de la obra es esencial para su completa valoración.

Lo mismo ocurre ahora que la poesía postmoderna desplaza el significado de unidad. Porque se puede traducir el fragmento de Zubieta que lleva el encabezado «Costanera Tower», pero, a diferencia de la traducción de «En perseguirme, Mundo, ¿qué interesas?», traduciendo «Costanera Tower», aunque sea con la misma hipotética bondad que se hizo con Sor Juana, el mismo hipotético alemán no podría acusar

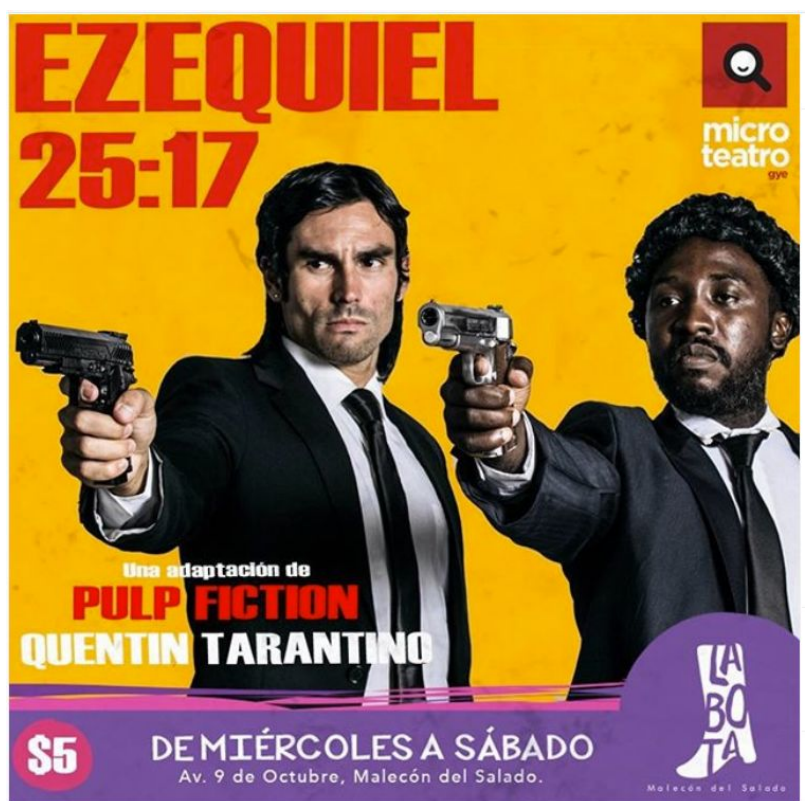
poemario, y ese fragmento separado por lo que llamamos un título, ése «Costanera Tower», es un capítulo, un movimiento, un episodio.

conocimiento alguno del poema, porque la unidad no está en «Costanera Tower», si no que está en Zubieta. Es, entonces, imposible una antología de Arriagada Zubieta que no incluya todo mismo poemario (como no se puede traducir el capítulo 42 de Moby-Dick y decir que se ha traducido toda la obra) pues en la postmodernidad el poema es el 
1.2 Límites del espacio, y otras tareas del traductor

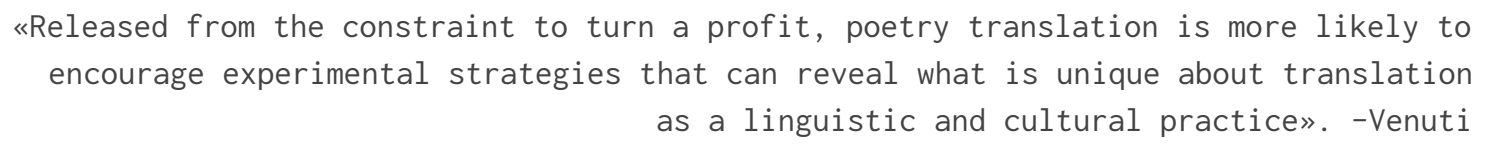

La realidad es que cuando se traduce poesía contemporánea -casi toda ella es postmoderna- los límites del espacio en el que se realiza la traducción -y quizás también los límites del entendimiento o del recuerdo del funcionamiento del fragmento en su contexto- imposibilitan que todo el poema se traslade. Esto es natural. No hay espacio para más. Pocas son las revistas literarias que traducen todo el poemario-poema. Pocos han de ser sus lectores. Bitácoras y redes sociales, espacios ahora de difusión con mayor alcance, también ven que generalmente se traduce una parte fragmentada de la unidad poética. Esto es también natural, la atención es, también, limitada. Los recursos son limitados; el tiempo del traductor, aún más.

Lo que no es natural, lo raro -quizás porque no se acostumbre, quizás porque se entiende que el lector es avezado- es que a la traducción no se la acompañe de una intervención del traductor o del editor donde se haga saber algo de la relación del fragmento con el todo, pues si al traductor se lo pide invisible, ¿̇cómo va a opinar? La respuesta al porqué tendría que chirriar la voz del traductor advirtiendo de las claves de lecturas del texto es, quizás, de Venuti, mas lo cierto es que, por lo menos en nuestro idioma, acercar el texto al lector en una breve introducción es una empresa que no se acomete- muy al detrimento de la poesía. Y tampoco se estila mediarlo, como veremos a continuación, cuando se toma un fragmento de un poemario y se lo reproduce sin contexto- tarea que podría ser de un oficioso editor. 


\section{Breves claves de Zubieta}

$$
\begin{array}{r}
\text { «Dime, plaza de nidos musicales, de las } \\
\text { actrices que impacientes por salir a la escena». } \\
\text {-Ramón López Velarde }
\end{array}
$$

$\mathrm{Al}$ momento de redacción de éste ensayo, enero de 2020, aparecen dos publicaciones digitales que recopilan fragmentos de la obra de Arriagada Zubieta. ${ }^{2}$ Convenientemente, ninguna de ellas interviene sobre lo ya intervenido. Es decir, sólo presentan los fragmentos seleccionados- el contexto queda más allá del margen, acusando precisamente la falta de un preámbulo editorial que comente ya no sólo la relación del fragmento elegido con el todo ausente, sino los criterios que puedan existir detrás de la selección de los pasajes. Mas quizás sea exagerado pedir que el crítico literario ejerza- aún cuando una de las publicaciones de las que hablamos clama ser «el primer diario digital de crítica cultural en sudamérica» ${ }^{3}$.

Lo que la publicación anterior de Arriagada Zubieta, Hotel Sitges, prefiguraba Zubieta lo subvierte. ${ }^{4}$ Si Hotel Sitges planteaba una relación amorosa a través del descubrimiento personal ante el telón de la ciudad gris y destruída, reflejo de la voz narrativa, Zubieta es prácticamente lo contrario: la ciudad, vista como espacio destruído y colonizado, está en el centro del escenario, y lo emotivo está pintado en el

\footnotetext{
2 «Los poesía visual de Rodrigo Arriagada-Zubieta: "Cuando ya no hay la vida de otros en la pantalla"», Cine y literatura, 4 de enero de 2020.

«Rodrigo Arriagada-Zubieta: como nenúfares en el charco», La libélula vaga, 5 de enero de 2020.

${ }^{3}$ Subtítulo en https://www.cineyliteratura.cl/ . La publicación Libélula vaga por lo menos le hace honor a su nombre.

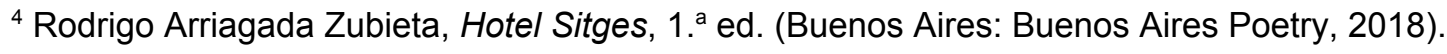


atrezzo. En aras de contrastar el gris oscuro que la repleta, está trabajado en Zubieta con particular atención aquello que, de cierta forma, se opone a la ciudad- la cual es vista como un no-lugar donde la identidad, caracterizada a través de la privacidad, se pierde: «[O]ímos trozos de conversaciones íntimas / condenados a ser vecinos idénticos, / pero desconocemos la voluntad del creador» ${ }^{5}$. Entonces, a lo largo de Zubieta los espacios que intentan batirse contra lo opaco de la ciudad, los parques y las plazas, poco a poco van cambiando de significación para ser embuchados por el asfalto que prima en la Ciudad y en las páginas que la traicionan: «Si alguien quiere un trozo de eternidad / tendrá que saltar las calles $[\ldots]^{6}{ }^{6}$.

No se debe suponer, entonces, que al final de la obra los espacios que otrora eran de esparcimiento mantienen las mismas connotaciones que tenían al inicio del poemario. Es casi irresponsable no advertir en los fragmentos que se toman del poemario cómo Arriagada Zubieta altera los significantes, para luego, tal como la ciudad hizo con las flores, cercenarlos y mostrarlos en una «compilación» sin contexto y no advertir sobre lo que sucede; este desdén editorial es pedirle al lector que se prepare para la piscina y echarlo al mar muerto. Es decirles que Jules acalla a los ladrones abriéndoles un maletín sin explicar qué relevancia ha tenido aquel dichoso objeto. O quien es Jules.

Volviendo a los elementos de Zubieta, es imprescindible reparar en el papel que desarrolla lo femenino, que si los espacios verdes son dinámicos en su obra, lo femenino es, en cambio, una constante en Zubieta- y en la obra del poeta; es un motivo que perdura, que no se logra conquistar nunca por la decadencia del territorio: es lo siempre estético, lo que siempre mitiga o condona: «Esa virgen y hada / que quizás nunca duerme / ahuyenta el miedo de los edificios pétreos $»^{7} \mathrm{o}$ «y el perfume

\footnotetext{
${ }^{5}$ Rodrigo Arriagada Zubieta, Zubieta, 1. ${ }^{\text {a }}$ ed. (Buenos Aires: Buenos Aires Poetry, 2019). 37.

${ }^{6}$ Arriagada Zubieta, Zubieta. 20.

7 Arriagada Zubieta, Zubieta. 32 y 33.
} 
florido de las estrellas / de un cuerpo femenino en cuartos ajenos ${ }^{8}$. El acercamiento a la mujer es lo que cambia en la páginas del poemario, la perspectiva de las voces narrativas, mas nunca el objeto en sí. Esta es la única clave esperanzadora de Zubieta, que lo constantemente estético existe, aunque mancillado por la poluta ciudad.

Aquí ha de mencionarse otra cuestión que se debe tener presente durante la lectura de Zubieta: la voz lírica -más bien narrativa- y la pluralidad de problemas que presenta. El cuestionamiento con el que narra-poetisa no es únicamente de la primera persona, no es propio del «yo». Muchas veces la voz narrativa apela a la segunda persona, táctica eficaz para lograr extrañamiento y suscitar dudas hacia la primera persona en el diálogo imposible entre el lector y el autor, o la voz lírica y el objeto cuestionado en su descripción: «Pero hoy eres adulto [...] $»^{9} \mathrm{O}$ «Pero iescucha! Soy el ciervo que se fugó de la selva» ${ }^{10}$. Este recurso casi exclusivo de la postmodernidad no lo trabaja nadie más como Arriagada Zubieta, que consigue evitar lo pedante de la segunda persona porque en su uso potencia el extrañamiento que suscita. Es decir, que si en otros usos poéticos de la segunda persona ésta, intentándose emplear en otros fines, genera como producto intencionado rareza, el acierto de Arriaga Zubieta es que la extrañeza que genera es el motivo por el que está usada.

Hay, por supuesto, códigos en Zubieta sobre los que aún no puedo especular porque no creo haberlos comprendido plenamente: las constantes alusiones homéricas y bíblicas: «volar como pájaros del árbol / del que fueron hojas finitas / estremecidas al contacto de la derrota $»^{11}$, «volver como un Ulises ardiendo / en la multitud de sus

\footnotetext{
${ }^{8}$ Arriagada Zubieta, Zubieta. 35.

${ }^{9}$ Arriagada Zubieta, Zubieta. 17.

${ }^{10}$ Arriagada Zubieta, Zubieta. 22.

${ }^{11}$ Arriagada Zubieta, Zubieta. 30. Recuerda al recurrente uso simbólico de Homero del árbol que pierde y gana hojas como huella del paso del tiempo, como en «[N]ow the brazen ax has stripped its barb and leaves» o "Like the generations of leaves, the lives of mortal men. / Now the wind scatters the old leaves across the earth, / and now the living timber bursts with the new buds [...]». Homer, The Iliad, trad. Robert Fagles (s. VIII a. e. v.; repr., Penguin Classics [Kindle], 1991). Libros 1 y 6, respectivamente.
} 
harapos» ${ }^{12}$, «[a]hora miramos al cielo / sin ninguna creencia, / hablamos distintas lenguas $[\ldots]^{13} »$, «[l]evántate y anda Lázaro»14, $\mathrm{o}$ «¿qquién removerá la piedra del sepulcro?» ${ }^{15}$. Por fortuna, para éste ejercicio quizás sólo el notarlo permita que prontamente lleguen las explicaciones, pero se comprende que hay algo aún por entender cuando es evidente el constante uso de imágenes bíblicas en una obra que no tiene ningún tipo de intención de reclamar a un ser divino el caos humano. ${ }^{16}$ Es decir, el aporte de las constantes referencias no lleva a un lugar de reflexión: quizás estén ahí para eso, para subvertir los grandes relatos al quitarles su relevancia. Aún es pronto para poder decir que se ha digerido lo recién masticado. Empero, hasta ahora, las alusiones homéricas recuerdan una suerte de heroísmo allí donde ya no existe ninguna posibilidad de ilíada, pues no hace eco del llamado a la aventura la negra sonoridad del hormigón.

Por último, si ya se han notado las constantes -el sosiego femenino- y las variables -los significados de los espacios comunes- el desasosiego es lo que queda en Zubieta: un retrato pesimista melancólico que no es de Santiago de Chile, si no que es de la lente de quien la transita, porque es la voz lírica la que decide la afectación del espacio, no el espacio el que habla por el individuo.

\footnotetext{
${ }^{12}$ Arriagada Zubieta, Zubieta. 34.

${ }^{13}$ Arriagada Zubieta, Zubieta. 13.

${ }^{14}$ Arriagada Zubieta, Zubieta. 33.

${ }^{15}$ Arriagada Zubieta, Zubieta. 27.

${ }^{16}$ Los versos de la nota cuatro remiten a esta misma idea.
} 


\section{3.}

Hay mucho más en Zubieta, por supuesto. Lo importante, si acaso haylo, es que no se pueden pasar por alto las cuestiones que la lectura suscita, porque el obrar del crítico, del antologador, del traductor, debe existir en una instancia más allá de ser la que acerca el texto sólo de una manera física, sin intervención intelectual. Así, tanto valdría que cualquier cosa se termine por publicar. Y hasta Netflix se permite medio párrafo para describir sus contenidos. Un tanto más podríamos trabajar nosotros.

\section{Bibliografía}

Arriagada Zubieta, Rodrigo. Hotel Sitges. 1. ${ }^{\mathrm{a}}$ ed. Buenos Aires: Buenos Aires Poetry, 2018.

---.Zubieta. 1. ${ }^{\mathrm{a}}$ ed. Buenos Aires: Buenos Aires Poetry, 2019.

Benjamin, Walter. «La tarea del traductor». En Teorías de la traducción, editado por Dámaso López García, traducido por Hans Christian Hagedorn, 1. a ed. Cuenca: Universidad de Castilla-La Mancha, 1996.

https://www.academia.edu/6313787/Walter Benjamin La tarea del tradu ctor traducci\%C3\%B3n de Hans Christian Hagedorn.

Cárdenas, Adrián. Ezequiel 25:17, 2017.

Crowe Ransom, John. «Criticism, Inc.» $V Q R, 1937$. https://www.vqronline.org/essay/criticism-inc-o.

Homero. The Iliad. Traducido por Robert Fagles. s. VIII a. e. v. Reprint, Penguin Classics [Kindle], 1991.

microteatro_gye. 15 de julio de 2017. https://www.instagram.com/p/BWi25Slg6 z/?utm source=ig web button share sheet.

Nida, Eugene A. Toward a science of translating: with special reference to principles and procedures involved in Bible translating. Leiden: E.J. Brill, 1964. https://archive.org/details/towardscienceoftoooonida/page/n7.

Tate, Allen. «Miss Emily and the Bibliographer». The American Scholar 9, n. ${ }^{\circ} 4$ (otoño de 1960): 449-60. 
Venuti, Lawrence. «Hijacking Translation: How Comp Lit Continues to Suppress Translated Texts». Boundary 2 43, n. ${ }^{\circ} 2$ (1 de mayo de 2016): 179-204. https://doi-org.libproxy.ncl.ac.uk/10.1215/01903659-3469952.

- - . «Introduction: Poetry and translation». Translation Studies 4, n. ${ }^{\circ} 2$ (1 de mayo de 2011): 127-32. https://doi.org/10.1080/14781700.2011.560014.

-- . The translator's invisibility: a history of translation. 1. ${ }^{\mathrm{a}}$ ed. 1995. Reprint, Londres: Taylor \& Francis, 2004.

Cine y literatura. «Los poesía visual de Rodrigo Arriagada-Zubieta: "Cuando ya no hay la vida de otros en la pantalla”», 4 de enero de 2020.

https://www.cineyliteratura.cl/los-poesia-visual-de-rodrigo-arriagada-zubiet a-cuando-ya-no-hay-la-vida-de-otros-en-la-pantalla/

La libélula vaga. «Rodrigo Arriagada-Zubieta: como nenúfares en el charco», 5 de enero de 2020.

http://lalibelulavaga.com/2020/01/05/rodrigo-arriagada-zubieta-como-nen ufares-en-el-charco/.

Nota:

Llicència de Creative Commons: Aquesta obra està subjecta a una llicència de Reconeixement 4.0 Internacional de Creative Commons. 